\title{
CHICKADEE SONG STRUCTURE IS INDIVIDUALLY DISTINCTIVE OVER LONG BROADCAST DISTANCES
}

\author{
by
}

\author{
PETER J. CHRISTIE ${ }^{1)}$, DANIEL J. MENNILL and LAURENE M. RATCLIFFE ${ }^{2)}$ \\ (Department of Biology, Queen's University, Kingston, Ontario, Canada K7L 3N6)
}

(Acc. 16-X-2003)

\section{Summary}

The two-note fee-bee song of male black-capped chickadees functions during the dawn chorus, in part, as a sexual signal across large distances. How song structure might encode information about male quality, however, remains unclear.

We studied the availability of cues to male social rank (a proxy indicator of male quality), within the acoustic structure of dawn chorus songs of male chickadees whose flock dominance status we determined the previous winter. We used analysis of variance and discriminant function analysis to demonstrate that five temporal, frequency or relative amplitude features of song can predict individual identity but not the category of social rank (dominant versus subordinate) to which individuals belong.

After transmitting chickadee songs through the forest and re-recording them at four broadcast distances, we found that song structure continued to effectively predict singer identity by our statistical methods despite significant acoustic degradation for as long as songs remained audible (up to $80 \mathrm{~m}$ ).

In particular, the relative frequency interval between the two notes is both the most invariant between-male measure and among the most individually distinctive.

1) Correspondence: Peter J. Christie, Department of Biology, Queen's University, Kingston, Ontario, Canada K7L 3N6; peter.christie@ cogeco.ca

2) We gratefully acknowledge the efforts of all the individuals who helped in collecting our recordings and in song analysis: Dev Aiama, Ryan DeBruyn, Amy MacDougall, Bridget Meigs and Nicole Vreeswyck Wilson. We also thank the management and staff of the Queen's University Biological Station for their support and John Toohey as well as the Curtis, Lundell, Warren, Weatherhead-Metzand Zink families for access to adjacent properties. This research was supported by American Ornithologists' Union research awards to P.J.C. and D.J.M., Animal Behavior Society research awards to P.J.C. and D.J.M., an E.A. Bergstrom Memorial Research Award to D.J.M., a Society of Canadian Ornithologists' Baillie Award to D.J.M., Natural Sciences and Engineering Research Council of Canada (NSERC) postgraduate scholarships to D.J.M. and an NSERC research grant to L.M.R. 
We conclude the structure of dawn chorus songs could function across large distances to signal the identity of familiar singing males whose relative quality is known to the listener from other interactions (such as encounters within winter flocks).

\section{Introduction}

Among the possible functions of bird song, the hypothesis that it can advertise relative male quality is broadly supported (Searcy \& Yasukawa, 1996). A less recognized requirement of advertisement models, however, is that in many circumstances the advertising characteristics of male song must be reliably discriminable to listeners across long distances. Studies of birdsong as an indicator of male quality and studies of the effects of transmission degradation on birdsong (usually in the context of providing cues to the distance, angular distance and elevation of the singer; Nelson \& Stoddart, 1998) typically belong to separate lines of inquiry. This reflects a view of signal design as either (1) a product of evolutionary forces acting on the signaller and the receiver (i.e. sexual selection) or (2) a product of the requirements to maximize a signal's transmission efficacy through the environment (Guilford \& Dawkins, 1991). Some crossover is evident in studies of sound degradation as a distance cue in male-male territorial interactions (McGregor \& Krebs, 1984; Fotheringham \& Ratcliffe, 1995; Naguib, 1996). However, few studies have looked at the interplay between the physical demands required in song transmission and song cues females rely on as honest indicators of male quality (but see Dabelsteen \& Pedersen, 1993; Mathevon et al., 1996). A polarized approach is inadequate when considering the role of birdsong structure in distant mate assessment by listening females.

Song structure (i.e. note frequency, duration or amplitude features) is one of a number of song traits - including song rate, duration and repertoire size (see review in Searcy \& Yasukawa, 1996) - implicated as a possible honest indicator of a singer's phenotypic or genetic quality. These subtle song parameters could reliably reflect variation in a male's ability to cope with the motor demands of sound production (Lambrechts, 1996; Podos, 1996; Suthers \& Goller, 1997; Suthers et al., 1999). Individual birds may also find it difficult to perform song elements that are close to the species limits for sound production imposed by body size (Ryan \& Brenowitz, 1985) or vocal tract configuration (Podos, 2001). Thus, even without repeated performances, features of song structure can provide information about the ability 
of a singer to overcome constraints if these features challenge the limits of sound production. In canary songs, for instance, Vallet et al. (1998) found females showed greater sexual response to songs with an apparently demanding syllable sequence ('sexy syllables') than those without, suggesting males able to perform this element are preferred by females. Similarly, the ability to maintain high amplitude during trills in the songs of dusky warblers was correlated with longevity and extra-pair paternity in that species (Forstmeier et al., 2002).

Alternatively, song structure could also signal male quality by providing individual recognition cues to listeners already familiar with the relative quality of the singer. The ability to distinguish individuals by their vocalizations has been well demonstrated in a variety of taxa (Andersson, 1994) and in birds, in particular (Falls, 1982; Godard, 1991; Stoddard, 1996). What cues are used in this discrimination is not well known. Falls (1982) suggests two categories of cues: distinctive combinations of song types or elements can signal individual identity in species with song repertoires (Gentner \& Hulse, 1998), or distinctive renditions of the same song type or element can also allow individual discrimination (often in species with single song types) (Nowicki, 1987; Weary \& Krebs, 1992; Lambrechts \& Dhondt, 1988). In the latter case, the distinctive cues reside in individual differences in fine structure of song. These structural differences can be spectrally complex, such as individually distinctive two-voice 'beats' produced in king penguin calls (Aubin et al., 2000), or subtle but distinctive temporal, frequency or amplitude cues (Weary \& Krebs, 1992; Dhondt \& Lambrechts, 1992).

Black-capped chickadees are socially monogamous, resident songbirds. In winter, chickadees form cohesive, territorial flocks of 4-12 birds (Smith, 1991). Birds in flocks demonstrate linear dominance hierarchies that can be discerned by observing interactions at feeders (Ficken et al., 1990). Highranking males in these flocks enjoy better access to food (Ficken et al., 1990), improved survival (Smith, 1991), and better overall reproductive success (Otter et al., 1999) than their low-ranking flockmates. Although pairing appears assortative by social rank, females commonly seek extra-pair copulations with males that rank higher than their social mates do (Otter et al., 1998; Mennill et al., 2002) and divorce their mates for males of higher rank when the circumstances arise (Otter \& Ratcliffe, 1996; Ramsay et al., 2000). The dawn chorus songs of male black-capped chickadees (a two-note fee- 
bee) appear to play a role in female mate choice (Otter \& Ratcliffe, 1993; Ratcliffe \& Otter, 1996), but how information about social rank is conveyed in song is not well understood. While females have been found to assess relative dominance status of males by 'eavesdropping' on patterns of response (signal conventions) in male-male territorial song contests (Mennill et al., 2002), how this relative quality is conveyed in the apparently 'solo' dawn in April and May is unclear. Otter et al. (1997) found dawn chorus start times, durations and song rates could be used discriminate between categories of high-ranking males and their lowest rank flockmates, but efforts to determine if chickadee song structure, per se, can predict this correlate of male quality have been less than conclusive (Chruszcz, 1995; Evans, 1999).

Song, however, is an acoustic long-distance signal. The capacity of song structure to provide cues to male quality or to male identity across large distances is thus confounded by sound attenuation and by sound degradation caused by obstacles, wind and other features in the environment. These features cause reverberation, selective frequency attenuation and irregular amplitude modulation that can degrade acoustic signals (Wiley \& Richards, 1982). Degradation depends on a number of factors, including the distance to the intended receiver, the nature of the habitat and topography, atmospheric conditions, the perch heights of singers and receivers, and, not least, the characteristics of the song being transmitted (Dabelsteen et al., 1993; Naguib, 1996). Song structure, therefore, is generally more vulnerable to environmental degradation than other potential song indicators of male social rank or identity such as repertoire, repertoire size or song output measures. The relationship between the amount of degradation in a signal and its propagation distance is not always predictable (Dabelsteen et al., 1993), but it is profound enough to permit many birds to use it for distinguishing near from distant songs (Morton, 1986; McGregor \& Krebs, 1984; McGregor, 1991; Naguib, 1995, 1997). Chickadees appear similarly capable of attending to structural degradation caused by distance propagation through the environment (Phillmore et al., 1998; but see Fotheringham \& Ratcliffe, 1995). If cues to male dominance status or individual identity reside in song structure (subtle differences in temporal, frequency and relative amplitude features), then these must survive or become enhanced by degrading environmental effects during song propagation. 
We analyzed a suite of five structural features, including temporal, frequency and relative amplitude measures, in the dawn chorus songs of male black-capped chickadees whose social dominance status in winter flocks was previously determined. We used analysis of variance and discriminant function analysis as statistical tools for determining if these song features were available as cues to relative social rank (categorically different between highranking and low-ranking flockmates) or, alternatively, as song cues to individual identity. We then broadcast recorded dawn chorus songs through the forest and re-recorded them at different transmission distances to determine if these available song structural cues could withstand the degrading effects of sound propagation. Few studies of structural acoustic cues to quality or identity in song birds have examined the realistic context of song transmission and the consequent degradation of song structure.

\section{Methods}

\section{Study site and subjects}

We studied the dawn chorus songs of male black-capped chickadees from among a population of colour-banded individuals at the Queen's University Biological Station north of Kingston, Ontario, Canada in the spring of 1999 and 2000. Chickadees were caught earlier at winter feeders and were sexed and aged using morphometric and plumage measures (Meigs et al., 1983; Desrochers, 1990; Smith, 1991). The relative social rank of subject males within their winter flocks was determined by monitoring interactions at feeders (using established methods; see Ficken et al., 1990; Otter et al., 1994). Social rank data used in this analysis were taken from the results of 4,860 interactions between $c a 152$ birds in 35 flocks that were part of a separate study (Mennill et al., 2002). High-ranking and low-ranking males were selected for paired comparison when they represented a flock's dominant male and his most subordinate male flockmate. These represented the alpha male and the beta male in 10 of the 25 flocks in our sample (i.e. only 2 males in these flocks). In the remaining 15 flocks, alpha males and their most subordinate male flockmates were separated by at least one other male (i.e. 3 male flocks) and as many as 3 (i.e. 5 male flocks).

\section{Song structure as a cue to identity}

We first tested whether the variability of frequency, temporal and relative amplitude features in male chickadee dawn chorus songs could provide listeners with cues to the identity of individual singers. We compared variability in these song features among and within males by analysing nine songs selected from a single dawn chorus performance from each of 46 males (a total of 414 songs). Recordings of entire or partial dawn choruses of territorial songs were made at dawn ( $\mathrm{ca}$ 04:45-06:30) during the pre-fertile and fertile period between April 24 and May 10, 1999 ( $N=10$ males $)$ and between April 23 and May 16, $2000(N=36$ males). Birds were recorded at distances of 4 to $8 \mathrm{~m}$ using SONY Walkman Professional 
Stereo Cassette Recorders (WM-D6C) or Marantz Portable Cassette Recorders (PMD222) and either a Sennheiser directional microphone (model BA3) or Audio-technica directional microphones (model AT815a) with Saul Mineroff pre-amplifiers (model BA3). Songs were digitized at a sampling rate of $22050 \mathrm{~Hz}$ (16-bit format) using Syrinx-PC sound processing software (John Burt, Seattle, WA) and analysed using Avisoft SASLab Pro sound analysis software for Windows (Raimund Specht, Berlin, Germany).

We used five song features in our analysis (Fig. 1). These were song length (seconds), the relative length of the fee note (fee length = percentage of song length), the relative loudness of the fee note (relative fee loudness = the logarithmic root mean squared measure (RMS) of the amplitude of the fee note $\left(\mathrm{V}_{\mathrm{Fee}}\right)$ expressed in decibels relative to the RMS value for the song $\left(\mathrm{V}_{\text {Song }}\right)$ ), the frequency ratios of the fee note (glissando ratio $=$ frequency at fee $e_{\text {start }} /$ frequency at fee $e_{\text {end }}$ ) and the internote interval (interval ratio $=$ frequency at fee $e_{\text {end }} /$ frequency at bee start $_{\text {f }}$ ) (see Weisman et al., 1990). The amplitude measure for the note and the song was determined using Avisoft software's 'copy RMS of marked section' analysis tool and the ratio in $\mathrm{dB}$ was calculated as $20 \log \mathrm{V}_{\mathrm{Fee}} / \mathrm{V}_{\text {Song }}$. We used a $2.5-5.0 \mathrm{kHz}$ bandpass filter to reduce background noise outside the relevant frequency band to $0 \mathrm{~dB}$ SPL. Spectrograms were generated with an FFT length of 1024 points and a spectral overlap of 87\% (Hann window, 100\% frame size). These parameters allowed a frequency resolution of $21 \mathrm{~Hz}$ and a temporal resolution of $5.8 \mathrm{~ms}$. The start and end of signal elements were considered the points at which the amplitude of the sound within the envelope was less than $10 \%$ relative to the signal's maximum as determined using the Avisoft software's automatic parameter measurements (settings: $-20 \mathrm{~dB}$ re max. amplitude, hold time $2 \mathrm{~ms}$ ). The $-20 \mathrm{~dB}$ threshold was chosen for its consistency for usefully delineating the signal while reducing the likelihood of interference from background noise. The absolute acoustic frequencies for the songs were determined by the frequency at the start of the second, more-constant bee note (Shackleton, 1991; Otter \& Ratcliffe, 1993).

While the general structural consistency of chickadee songs have been noted by several authors (e.g. Hailman, 1989; Kroodsma et al., 1999), chickadees are capable of varying the absolute frequency of these songs up and down a continuous range of several hundred hertz (Horn et al., 1992). In separate analyses, we found that many of the fine structural features of chickadee song chosen for this study showed change with changes in the absolute frequency of song performance (Christie et al., in press). That is, songs became significantly shorter with shorter, relatively quieter fee notes when singers 'pitch shifted' songs up the continuous $2770-3630 \mathrm{~Hz}$ frequency range. Thus, all analyses in this study were performed on song feature values standardized for frequency. To achieve this, we calculated 'best fit' linear regressions for each song feature and the residuals to this fit for each data point. We then added these residuals to the mean value for each song feature at the median frequency for all songs $(3200 \mathrm{~Hz})$.

We calculated the grand mean and standard error for all song features for all birds. We also determined the between-male coefficients of variation $(\mathrm{CV}=[\mathrm{SD} /$ mean $] \times 100)$ and the average within-male coefficients of variation based on the values from the songs of each male. The ratios of between-male to within-male coefficients of variation $\left(\mathrm{CV}_{\mathrm{b}} / \mathrm{CV}_{\mathrm{w}}\right)$ were used as a measure of relative between-male variability for each song feature. A value of $\mathrm{CV}_{\mathrm{b}} / \mathrm{CV}_{\mathrm{w}}>1$ suggests a song feature is more variable between individuals relative to its variability within individuals and could be used as a cue to individual identity (Bee $e t$ al., 2001). The significance of differences in song features between males was tested using analysis of variance (ANOVA). To meet the assumptions of all parametric tests in these 


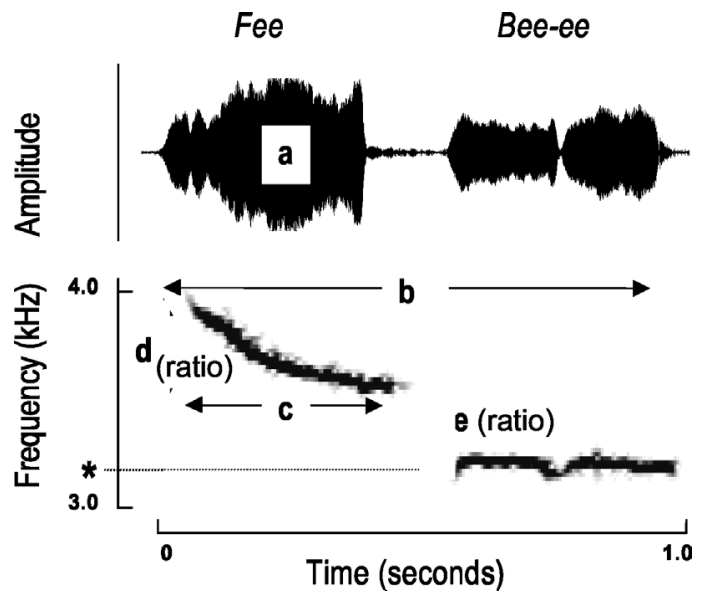

Fig. 1. An oscillogram and spectrogram representing a typical male black-capped chickadee song from a dawn chorus recording. Song structural measures included in our analysis were (a) Relative Fee Loudness (dB), (b) Song Length (seconds), (c) Fee Length (\%), (d) the Glissando Ratio and (e) the Interval Ratio. The absolute frequency of songs was calculated as the frequency of the start of the bee note $(*)$.

analyses, an arcsine transformation of the fee length measure and a Box-Cox transformation of the relative fee loudness measure were employed to ensure the distributions of these parameters approached normality (Sokal \& Rohlf, 1995). All statistical analyses were carried out using JMP IN 4.0.2. (SAS Institute Inc.).

We then tested whether the combination of the five features for each song could correctly classify songs as belonging to each of the chorusing male chickadees using a 'typical' combination of multivariate analysis of variance (MANOVA) and discriminant analysis techniques (Silva \& Stam, 1995). MANOVA was used to suggest whether the songs of individual singers were more statistically similar than the songs of all singers. Both descriptive and predictive discriminant analysis methods were used to explore the factors behind these differences and their reliability in classifying songs correctly. We used canonical variate analysis as a descriptive tool to evaluate how well linear combinations of the five song measures (canonical variates) could optimally separate songs according to the identity of the singer. This was reliably done using eigenvalues (the sample variance of projected data points) and associated eigenvectors (cosines of the angles between the original variable axis and the corresponding canonical axis; a measure of variable 'loading' on each axis; Campbell \& Atchley, 1981). Predictive discriminant function analysis allowed classification of songs according to the first linear combination of the five song features (the first canonical discriminant function) that best separated songs according to singers. We assigned songs to individual singers according to a cross-validation technique (Bee et al., 2001) that generates discriminant functions for classification based on the data set with $N-1$ remaining songs.

Male chickadees in our population sing from often irregularly shaped territories of $152.25 \pm 27.48 \mathrm{~m}$ (mean $\pm \mathrm{SE}$ ) diameter (Mennill et al., in press). These are typically contiguous with one or several other territories. We found chickadee songs transmitted at $80 \mathrm{~dB}$ SPL were not quantifiably discernible above ambient forest noise when recorded at $100 \mathrm{~m}$ 
within one hour of dawn. We conclude from this and from field observations that chickadee song propagation at $80 \mathrm{~dB}$ SPL is unlikely to reach a maximum radius of more than two territories beyond the singer's own. We used this information, as well as information about the geographic distribution of males in our sample and the fact that these represent singers from separate years to conclude that the full sample of 46 males potentially exaggerates the individual recognition problem facing the DFA classification.

In our sample from the population (which includes only two birds from each flock), individual recognition challenges were unlikely to require discrimination from among more than 10 males at once. Most often, depending on the geography, recognition tasks would require discrimination from among less than 10 (Mennill et al., in press). Therefore, we performed DFA discrimination using overlapping geographic groups of 10 singing males (5 groups of 2000 males and 1 group of 1999 males) to determine an overall average success in predicting singer identity. For comparison, we calculated expected results by determining the number of songs that would be attributed to the correct singer by random assignment. We also repeated the DFA using 10 groups of 10 males randomly chosen from our sample of 46 birds. These results yielded similar overall average predictability.

\section{Song structure as a cue to relative social rank}

We used the measures and variability of the five acoustic features to explore whether male chickadee songs could provide cues to the relative social rank of singers. We compared these features between pairs of chorusing males representing the most dominant birds and their most subordinate flockmates from each of 3 winter flocks in 1999 and 18 flocks from $2000(N=42$ males). (Birds that were not paired high-ranking and low-ranking flockmates were not used in this analysis.) We measured the five song features of nine songs from each male (378 songs) according to the methods described above and corrected them for absolute frequency. We calculated the grand mean and standard error for all song features and calculated the average within-male CV for high-ranking and low-ranking birds. We compared the song structure of high-ranking $v s$. low-ranking males by flock using paired $t$-tests of the average values and $\mathrm{CV}$ for the five acoustic features for each male ( $N=21$ flocks).

\section{Song structure and transmission distance}

We conducted song transmission experiments in early May 1999 and 2000, during the period before leaves develop on trees, in a moderately dense deciduous forest $5.5 \mathrm{~km}$ from the Queen's University Biological Station. The vegetation at the transmission site (Acer spp., Fraxinus spp., Carya spp., Ostrya virginiana, Quercus spp., Betula spp.) is similar to the vegetation of the territories of the recorded males, and the topography is level. (The transmission site was located entirely within the known territory of a pair of black-capped chickadees that was not part of this study.) Transmission experiments were performed at or shortly after dawn and were contemporaneous with the natural chickadee dawn chorus.

Sound files for the transmission experiment consisted of songs recorded from the dawn choruses of male chickadees (see above). These songs were normalized for amplitude and broadcast through the forest using a SONY Sports Walkman (model WM-FS191) and a SONY Active Speaker System (model SRS-77G). The songs were broadcast at an amplitude of $80 \pm 3 \mathrm{~dB}$ SPL as measured at $1 \mathrm{~m}$ from the speaker with a Realistic Sound Level Meter (model 33-2050). The speaker was set at $2 \mathrm{~m}$ from the ground - a height not atypical of 
song posts used by many chorusing males in the population (pers. obs.). The songs were then re-recorded at 4 distances $\left(5,40,60\right.$ and $80 \mathrm{~m}$ ) along a single transect (along a $220^{\circ}$ compass bearing). Attempts to consistently record the songs at $100 \mathrm{~m}$ proved fruitless since all or parts of the signals were often inaudible above the ambient noise at that distance and could not be accurately measured. The songs were re-recorded using a Marantz Portable Cassette Recorder (PMD222) and a Sennheiser omni-directional microphone (model K6-C) set at a height of $2 \mathrm{~m}$.

For our initial analysis of changes to song structure caused by distance propagation, we selected only songs that were clearly audible at all of the recording distances (recorded songs free from the confounding and stochastic sound-masking effects of other bird song, loud overhead planes or other loud noise). This permitted clear comparisons between songs to isolate the 'usual' ambient environmental degradation that occurs with transmission distance. This analysis involved 100 songs from 19 birds. Transmission re-recordings were then digitized, filtered and analysed in the manner described above. We used repeated measures ANOVAs to assess whether the five structural features of male chickadee songs were significantly altered by the degrading effects of transmission across four distances $(5,40,60$ and $80 \mathrm{~m})$ through the forest. Post hoc tests for significant differences between pairs of transmission distances for each structural measure were determined using paired $t$-tests.

We explored whether distance transmission changed the reliability of song structure to identify individual singers by comparing the results of discriminant function analyses performed at each distance. This analysis used a subset of 12 birds from the sample where an adequate number of songs from each male (6-8 songs) were audible and could be measured at all distances. To meet the assumptions of our significance tests in this analysis, we used a logarithmic transformation of the fee length and a Box-Cox transformation of the relative fee loudness measure.

\section{Song transmission and social rank}

We examined whether distance transmission of male songs may have an impact on the relationship between social rank and song structure. For this analysis, we compared the average values for each of the five acoustic measures from the songs of 10 high-ranking males and 10 low-ranking males from 11 flocks (i.e. 9 high-ranking males and their 9 low-ranking flockmates as well as one high-ranking male and one low-ranking male from separate flocks). We calculated the grand mean and standard error for all song features for songs each from high rank and low-ranking birds at each distance. We compared the song structure of high-ranking $v s$. low-ranking males by flock using paired $t$-tests of the average values of the five acoustic features at each distance.

\section{Results}

Can song structure provide cues to individual recognition?

The $\mathrm{CV}_{\mathrm{b}} / \mathrm{CV}_{\mathrm{w}}$ ratios indicated all five structural features of chickadee dawn chorus songs were relatively more variable between males than within males (Table 1). The ANOVAs showed this relationship of within-male and 
between-male variability is significant for each song measure and that these acoustic features could provide recognition cues to the identity of the singers. A multivariate analysis of variance for our sample confirmed song structure for each individual was significantly distinctive to permit the recognition of singers by their song (MANOVA, Wilks' Lambda $=0.03$, Approx. $\left.F_{225,1816}=7.5, p<0.0001\right)$. Evaluation of the canonical coefficients in this analysis showed the first canonical axis, which accounted for $51.6 \%$ of the song variation between males, used song duration and two frequency ratios (glissando ratio and the interval ratio) to explain much of the betweenmale song variation. Interestingly, the interval ratio, the structural measure with the smallest variation, nevertheless is weighted most heavily in explaining variation in the second discriminant function (accounted for $21.2 \%$ of the between-male variation), followed by the glissando ratio. The third discriminant axis, which described a further $15.5 \%$ of individual variation, was weighted most heavily on the glissando ratio. Meanwhile, the relative length of the fee note and the relative loudness of the fee contributed little to the canonical discrimination between individuals.

Subsequent discriminant function analyses provided a picture of the accuracy of using the five song structural features to distinguish songs of individual singers. To evaluate the accuracy of using our subsamples of 10 birds for this analysis we tracked the change in DFA song classification accuracy with increases in the number of birds randomly chosen from our sample (Fig. 2). We found accuracy changes by less than $10 \%$ (9.6\%) whether discriminating between 10 males or 20 . Accuracy improves quickly when discriminating from among less than 10 males. For the six selected groups of 10 individuals, these analyses show our canonical discriminant functions allowed for the mean correct classification of $64.1 \%$ of songs by individual singer (range $52.2-74.4 \%$ ), well above the chance correct assignment of songs to singer of $11.1 \%$. Repeating the discriminant function analyses using the songs of 10 groups of 10 randomly chosen birds from our sample of 46, the mean correct classification of songs was a similar $62.2 \%$ across all groups (range $52.2-80.0 \%)$.

Can song structure provide cues to relative social rank?

All five acoustic measures used in our comparisons showed no difference between those in songs performed by chorusing high-ranking males and those 


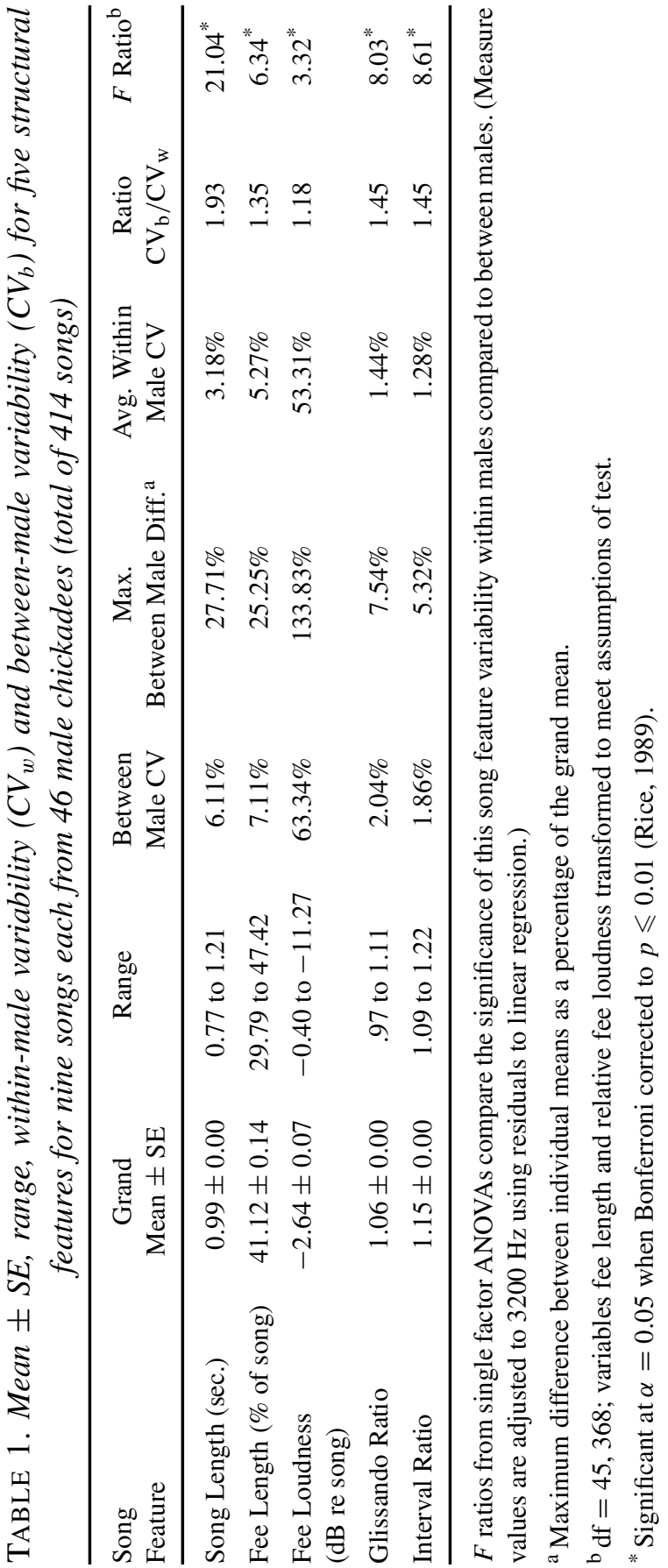




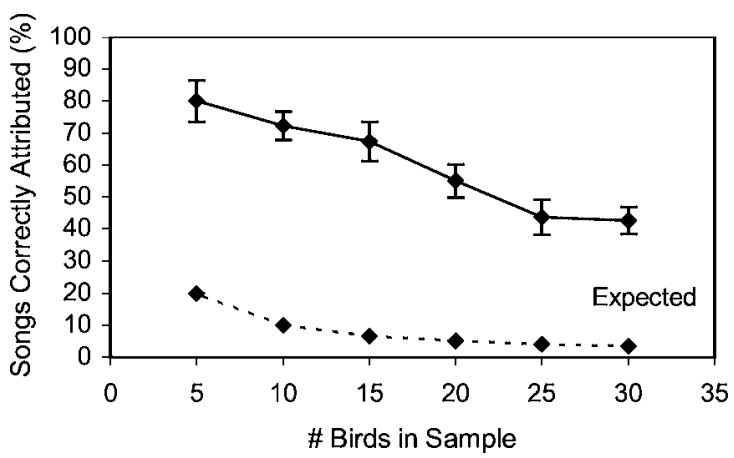

Fig. 2. The predictive accuracy of discriminant functions (using five song features for nine songs from each bird) for correctly attributing songs to their singers with the change in the number of individual birds (randomly) included from our sample (solid line). Also included for comparison is the number of songs expected to be attributed correctly if songs were randomly assigned to singers (dashed line).

performed by their low-ranking flockmates in 21 flocks (Table 2). Similarly, high-ranking and low-ranking males showed no significant difference in the amount of variability (CV) for each of the measures. Although we have little idea how much difference in the values of acoustic features between highranking and low-ranking birds is biologically meaningful, we expect differences to be of a magnitude that is readily discernible if they are to categorize songs by the relative rank of the singers. Post hoc power analyses provided some confidence in our conclusions that no significant differences exist. The five acoustic song measures from our pairs of high-ranking and low-ranking birds from $N=21$ flocks provide adequate power to reliably distinguish a $2.5 \%$ difference in song duration, a $1 \%$ difference in the fee length, a $12 \%$ difference in the relative fee loudness, and about a $1 \%$ difference in the glissando and interval frequency ratios.

\section{Does song structure change with transmission distance?}

The structure of male chickadee songs changes when songs are broadcast through the forest. Recorded songs of chickadees transmitted through the forest at $80 \mathrm{~dB}$ SPL and re-recorded at 5, 40, 60 and $80 \mathrm{~m}$ showed significant structural change with transmission distance as measured by four of our five structural measures; only the interval ratio remained impervious to degradation across broadcast distances (Repeated measures ANOVAs: Interval ratio, $F_{3,97}=2.26, p=0.0868$; song length, $F_{3,97}=27.58, p<0.0001$; fee 


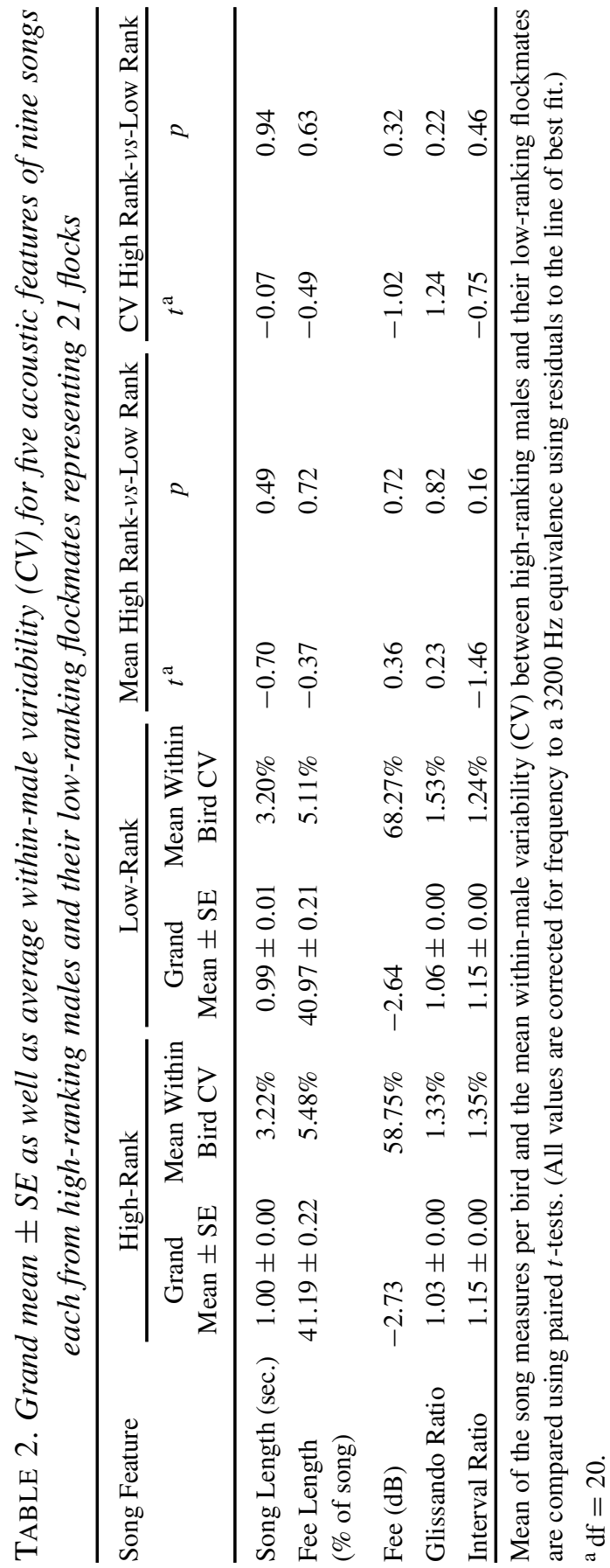


length, $F_{3,97}=15.74, p<0.0001$; relative fee loudness, $F_{3,97}=15.71$, $p<0.0001$; glissando ratio, $F_{3,97}=17.79, p<0.0001$; Fig. 3 ).

\section{Do songs remain individually distinctive across transmission distances?}

Despite significant structural degradation resulting from broadcast through the forest, most song traits remained significantly individually distinctive at all but the $80 \mathrm{~m}$ transmission distances, with the exception of relative fee loudness. The interval ratio was significantly distinctive at all transmission distances (Table 3). Discriminant function analyses, meanwhile, showed the mean classification success generated by canonical discriminant functions combining the five structural measures diminished somewhat but not significantly with broadcast distance (Fig. 4; Repeated measures ANOVA, $F_{3,6}=1.72, p=0.26$ ). Classification success at all distances nevertheless remained far higher than would be expected by chance.

\section{Song transmission and social rank}

Song structural measures of high-ranking males and their low-ranking flockmates showed no difference when re-recorded at four broadcast distances ( 5 , $40,60$ and $80 \mathrm{~m})$ through the forest $(4 \times 5$ paired $t$-tests: all $t<1.89$, all $\mathrm{df}=8$, all $p>0.09$ ). In other words, changes in song structure due to sound degradation did not improve discrimination between songs of high- or low-ranking males at optimal transmission distances.

\section{Discussion}

Recent studies suggest subtle structural differences in the way individual birds sing even simple songs may reflect their ability to cope with the physiological limitations of sound production (Podos, 1996, 2001; Suthers \& Goller, 1997; Suthers et al., 1999). These song structural differences, thus, may provide honest indicators of male phenotypic or genetic quality if they are costly to sing well (Vallet et al., 1998; Forstmeier et al., 2002), costly to sing consistently over repeated performances (Lambrechts, 1996), or costly to learn (Nowicki et al., 1998, 2000). Our results suggest that this may not be true in the case of structural differences in the fee-bee songs of male blackcapped chickadees. We found no evidence that the structural features examined in this analysis could provide listeners with reliable categorical cues to 
a

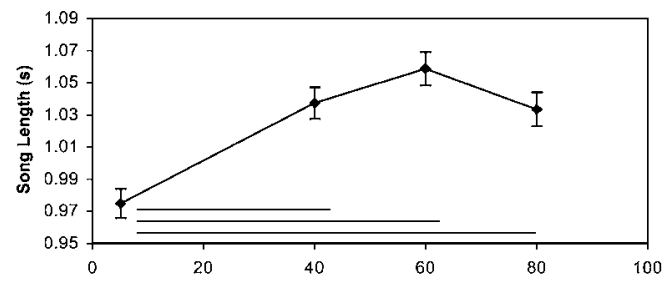

b

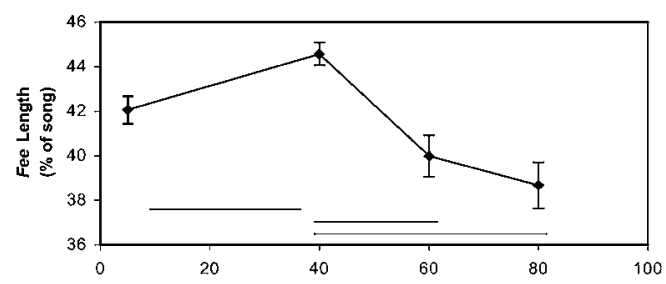

$\mathrm{c}$

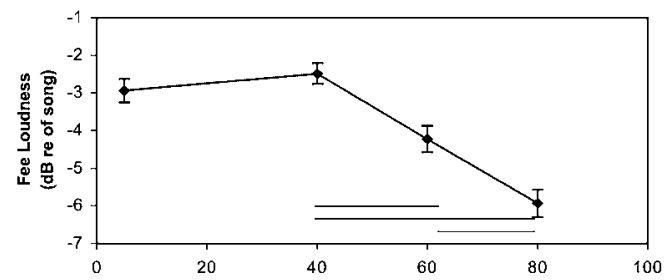

d

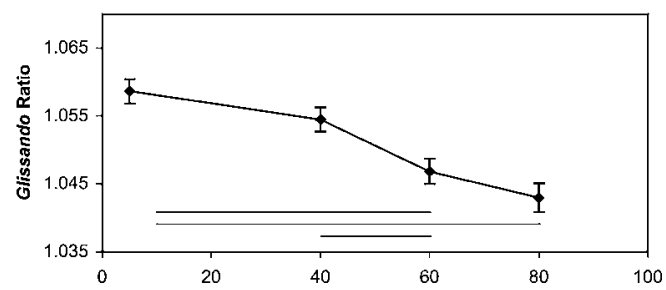

$\mathrm{e}$

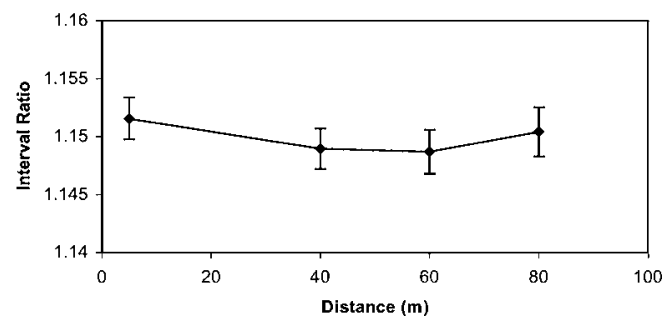

Fig. 3. Changes in five structural features of chickadee song across four transmission distances $(5,40,60$ and $80 \mathrm{~m})$ for 122 songs (from 20 males). Significant differences from pairwise comparisons using matched paired $t$-tests are indicated by lines. All values are corrected for frequency to a $3200 \mathrm{~Hz}$ equivalence using residuals to the line of best fit. 
TABLE 3. Mean $\pm S E$ along with between-male variability $\left(C V_{b}\right)$ and withinmale variability $\left(C V_{w}\right)$ for five song structural features measured from songs recorded at each of four transmission distances

\begin{tabular}{|c|c|c|c|c|c|c|c|}
\hline \multirow{2}{*}{$\begin{array}{l}\text { Song } \\
\text { Trait }\end{array}$} & \multirow{2}{*}{$\begin{array}{l}\text { Transmission } \\
\text { Distance }(m)\end{array}$} & \multicolumn{2}{|c|}{ Between Birds } & \multicolumn{2}{|c|}{ Within Birds (Avg.) } & \multirow{2}{*}{$\begin{array}{c}\text { Ratio } \\
\mathrm{CV}_{\mathrm{b}} / \mathrm{CV}_{\mathrm{w}}\end{array}$} & \multirow{2}{*}{$\begin{array}{c}F \\
\text { Ratio }^{\mathrm{a}, \mathrm{b}}\end{array}$} \\
\hline & & Mean \pm SE & $\mathrm{CV}_{\mathrm{b}} \%$ & Mean \pm SE & $\mathrm{CV}_{\mathrm{w}} \%$ & & \\
\hline \multirow{4}{*}{$\begin{array}{l}\text { Song } \\
\text { Length } \\
(\mathrm{sec} .)\end{array}$} & 5 & $0.96 \pm 0.01$ & 9.47 & $0.97 \pm 0.02$ & 4.83 & 1.96 & $19.59^{*}$ \\
\hline & 40 & $1.03 \pm 0.01$ & 9.92 & $1.03 \pm 0.02$ & 5.96 & 1.66 & $13.61^{*}$ \\
\hline & 60 & $1.08 \pm 0.01$ & 10.65 & $1.08 \pm 0.03$ & 7.09 & 1.50 & $9.79^{*}$ \\
\hline & 80 & $1.04 \pm 0.01$ & 10.79 & $1.04 \pm 0.04$ & 10.14 & 1.06 & 1.17 \\
\hline \multirow{4}{*}{$\begin{array}{l}\text { Fee } \\
\text { Length } \\
(\%)\end{array}$} & 5 & $41.72 \pm 0.70$ & 15.57 & $41.62 \pm 1.90$ & 12.47 & 1.25 & $6.28^{*}$ \\
\hline & 40 & $44.54 \pm 0.60$ & 11.46 & $44.41 \pm 1.63$ & 9.91 & 1.16 & $6.26^{*}$ \\
\hline & 60 & $40.13 \pm 1.05$ & 23.49 & $39.86 \pm 3.49$ & 23.60 & 1.00 & $3.95^{*}$ \\
\hline & 80 & $37.33 \pm 1.20$ & 29.29 & $37.11 \pm 3.29$ & 24.58 & 1.19 & 2.04 \\
\hline \multirow{4}{*}{$\begin{array}{l}\text { Relative } \\
\text { Fee } \\
\text { Loudness } \\
(\mathrm{dB})\end{array}$} & 5 & $-2.74 \pm 0.35$ & 118.27 & $-2.75 \pm 1.17$ & 113.31 & 1.04 & 1.23 \\
\hline & 40 & $-2.16 \pm 0.32$ & 125.95 & $-2.19 \pm 0.92$ & 101.76 & 1.24 & 0.93 \\
\hline & 60 & $-4.10 \pm 0.41$ & 89.75 & $-4.19 \pm 1.18$ & 77.68 & 1.16 & 1.29 \\
\hline & 80 & $-6.67 \pm 0.57$ & 60.77 & $-6.85 \pm 1.18$ & 49.37 & 1.23 & $4.34^{*}$ \\
\hline \multirow{4}{*}{$\begin{array}{l}\text { Glissando } \\
\text { Ratio }\end{array}$} & 5 & $1.06 \pm 0.00$ & 1.67 & $1.06 \pm 0.01$ & 1.20 & 1.39 & $6.34^{*}$ \\
\hline & 40 & $1.05 \pm 0.00$ & 1.58 & $1.05 \pm 0.01$ & 1.16 & 1.36 & $6.27^{*}$ \\
\hline & 60 & $1.05 \pm 0.00$ & 1.75 & $1.05 \pm 0.01$ & 1.36 & 1.27 & $3.97^{*}$ \\
\hline & 80 & $1.04 \pm 0.00$ & 1.99 & $1.04 \pm 0.01$ & 1.75 & 1.14 & 2.06 \\
\hline \multirow{4}{*}{$\begin{array}{l}\text { Interval } \\
\text { Ratio }\end{array}$} & 5 & $1.15 \pm 0.00$ & 1.77 & $1.15 \pm 0.01$ & 1.13 & 1.57 & $9.10^{*}$ \\
\hline & 40 & $1.15 \pm 0.00$ & 1.91 & $1.15 \pm 0.01$ & 1.19 & 1.61 & $10.64^{*}$ \\
\hline & 60 & $1.15 \pm 0.00$ & 2.23 & $1.15 \pm 0.01$ & 1.65 & 1.35 & $4.86^{*}$ \\
\hline & 80 & $1.15 \pm 0.00$ & 2.07 & $1.15 \pm 0.01$ & 1.27 & 1.63 & $10.68^{*}$ \\
\hline
\end{tabular}

Individual distinctiveness is tested using single-factor ANOVAs at each distance. (All values are corrected to $3200 \mathrm{~Hz}$ using residuals to the line of best fit.)

a $5 \mathrm{~m} \mathrm{df}=11,75 ; 40 \mathrm{~m} \mathrm{df}=9,62 ; 60 \mathrm{~m} \& 80 \mathrm{~m} \mathrm{df}=10,67$.

${ }^{\mathrm{b}}$ To meet assumptions of significance tests, fee length was transformed using a log transformation, relative fee loudness using Box-Cox transformation.

${ }^{*}$ Significant at $\alpha=0.05$ when Bonferroni corrected to $p<0.0026$ (Rice, 1989).

discriminate between singers that were the highest or lowest rank male from winter flocks - categories of relative quality in terms of reproductive potential, resource holding ability, longevity and experience (age). This remained true when songs were heard from long distances. We also found no rankcategorical differences in the consistency of these song structural elements in an individual's dawn chorus performance. 


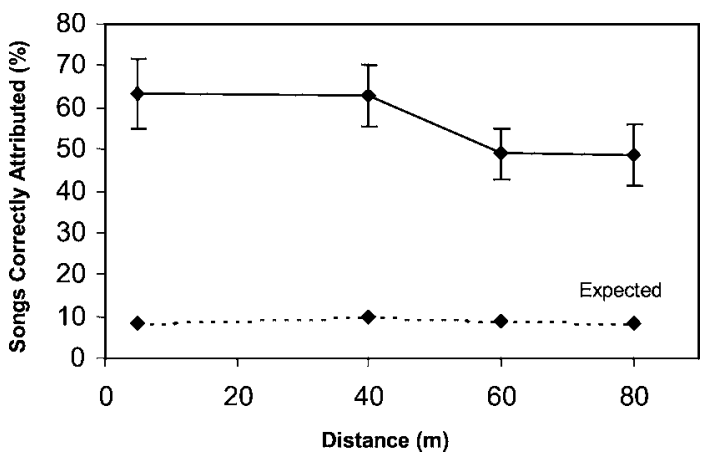

Fig. 4. Mean percent success $( \pm \mathrm{SE})$ of song classification by male singer at each of four transmission distances based on canonical discriminant functions combining the five acoustic features for 6-8 songs from each of 12 birds at 5 and $80 \mathrm{~m}, 10$ birds at $40 \mathrm{~m}$ and 11 birds at $60 \mathrm{~m}$ (solid line). Also included for comparison is the number of songs expected to be attributed correctly if songs were randomly assigned to singers (dashed line).

Why chickadee song should not fall in line with the growing literature implicating song structure as an honest indicator of male quality (e.g. Vallet et al., 1998; Forstmeier et al., 2002) is unclear. There may be simply nothing particularly demanding for a chickadee in performing one of the simplest of oscine songs (Hailman, 1989). Indeed, the widespread conformity to this learned song across the species range (Kroodsma et al., 1999) may imply that aspects of normal chickadee song structure are well within performance or developmental constraints for this species. Listening conspecifics (such as females assessing mating opportunities) may, instead, find adequate acoustic indicators of relative male social rank (quality) in the song rate of singing males during the dawn chorus (Otter et al., 1997) or by eavesdropping on the outcomes of territorial song duels between territorial males (Mennill et al., 2002).

Another explanation for our failure to find rank-related structural differences in chickadee songs may be that the five measures chosen here do not include those that provide the best indicators of relative male quality. Work studying the physiological constraints on sound production suggests that, in some cases, only a limited number of birdsong structural elements may place performance demands on singers (Suthers \& Goller, 1997). Sound amplitude, for instance, is not well studied but appears to be a likely candidate as a cue to a singer's sound production capacity (Podos, 1996). We found no rank-categorical difference in our relative measure of fee note amplitude 
in chickadee song. But further research should examine the possibility that high-ranking males differ from low-ranking males in their ability to sing louder songs (as an absolute measure) during the dawn chorus. Another possible song structural cue to male quality missed in this analysis is the combined effect of variation in more than one song structural feature. In a separate study, we suggest the dawn chorus songs of low-ranking males can be distinguished from those of high rank males by variation in the interval ratio that accompanies shifts in song pitch (Christie et al., in press).

However, significant song structural differences do exist between the dawn chorus songs of individual males. Indeed, our suite of song measures allowed for an effective classification of songs by singer using discriminant function analysis (mean $64.1 \%$ of song correctly attributed in 6 groups of 10 singing birds). Since distinctiveness determines the limit on recognition, the extent to which individuals can be accurately identified by their signals reflects the likelihood that these signals are useful for individual discrimination (Falls, 1982). An alternative to the hypothesis that chickadee song structure provides an honest cue to relative male social rank, therefore, is the idea that female chickadees can recognize the songs of individual males whose relative rank is already known to them.

Singers in many other songbird species can be individually recognized or, at least, distinguished from other singers by distinctive structural features in their songs (Falls, 1982; also see Stoddart, 1996 for review). Male chickadees could similarly benefit from acoustic cues that allow individual recognition during territorial encounters, reducing the unnecessary effort of repeatedly confronting known neighbours. Whether chickadees are capable of this in the wild has not been demonstrated. But Phillmore et al. (2002), using go/no-go operant experiments, found adult male chickadees in the lab could be readily trained to discriminate among familiar and novel songs of individual chickadees. The authors did not identify the likely cues used in this discrimination. In the present study, song length was an effective predictor of singer identity and played a large role in the overall statistical discrimination of individual birds. Much less is known about the ability of female songbirds to recognize songs of individual singers (Searcy, 1992). If cues to identity within dawn chorus songs are useful to female chickadees assessing mating opportunities, these females must be familiar with the singers and their song well before they settle on breeding territories in the spring. In the wild, singing is uncommon in the fall and early winter, but it becomes 
more frequent from late December through to its peak in the spring (Smith, 1991). The sporadic early winter singing may function to sufficiently expose flockmates to song structural 'signatures' before flock break up in April.

The degradation of sound during propagation through the environment is increasingly recognized as an evolutionary constraint in acoustic distance communication (see review in Endler, 2000). The structure of bird song, for example, is always attenuated and degraded to some degree - by reverberation, frequency-dependent attenuation and irregular amplitude modulation - by the time it reaches a receiver. This can interfere with the capacity of song to convey information. Structural features like song rhythm (i.e. lengths of notes and note intervals), for example, might reasonably be expected to become confounded by reverberation that fills in between notes when songs are broadcast across large distances. Our experimental broadcasts demonstrated that four of our five chickadee song structural features degraded significantly after being transmitted for distances of up to $80 \mathrm{~m}$. Fotheringham \& Ratcliffe (1995) found similar degradation of chickadee songs broadcast in a forested environment. In that study and this, significant effects of reverberation increased song length at middle distances while attenuation shortened duration measures at maximum distances. Unlike that study, however, our observed changes in the relative amplitude of the fee note as well as the glissando ratio suggest disproportionate attenuation of higher frequency song elements at large distances. Neither frequency dependent attenuation nor any other aspect of sound degradation had any impact on the interval ratio, which alone remained impervious to the deleterious effects of song transmission (again similar to the findings of Fotheringham \& Ratcliffe, 1995).

Although chickadee song distance transmission altered most of the structural features in our analysis, their effectiveness in permitting statistical discrimination of songs by singer did not dramatically diminish (although it did diminish somewhat). Our findings suggest the dawn chorus songs of male chickadees can nevertheless provide individual recognition cues when heard at large distances, such as from neighbouring territories. Again, these results are in keeping with operant studies that suggest, while male chickadees discriminate environmentally degraded from undegraded song (Phillmore et al., 1998; but see Fotheringham \& Ratcliffe, 1995), song degradation does not interfere with their ability to discriminate individual singers by song across at least a moderate broadcast distance of $25 \mathrm{~m}$ (Phillmore et al., 2002). 
Among the structural cues examined in this analysis, the interval ratio was among the most important features for identifying males by their song. It was also the only feature under analysis that remained unaffected by transmission degradation for broadcast distances of up to $80 \mathrm{~m}$ and individually distinctive as long as songs were audible. The interval ratio (as well as the fee ratio) have been implicated as cues to species recognition for chickadees (Weisman \& Ratcliffe, 1989; Shackleton et al., 1992). The remarkable stereotypy of these two features (showing less than $2 \%$ variation) across most of the species' range (Kroodsma et al., 1999) and within our Eastern Ontario population lends support to this notion. Shackleton et al. (1992) suggested the highly repeatable nature of these structural characteristics supports the 'invariant features hypothesis' (Marler, 1960), which suggests signal cues important for species recognition are subject to strong stabilizing selection. Signal features that provide indicators of a signaler's quality (fitness) or identity, on the other hand, should be much more variable between males. Results from the present study suggest this rule of thumb can be misleading; some signal characteristics can be highly stereotyped between individuals and yet even more invariable within individuals. Thus, listening chickadees may find the interval ratio provides a consistent species indicator that is impervious to sound degradation during distance transmission. They may also find, by paying attention to the same resilient feature, that they can determine the identity of individual singers.

\section{References}

Andersson, M. (1994). Sexual selection. - Princeton University Press, Princeton, NJ.

Aubin, T., Jouventin, P. \& Hildebrand, C. (2000). Penguins use the two-voice system to recognize each other. - Proc. R. Soc. Lond. B 267, p. 1081-1087.

Bee, M.A., Kozich, C.E., Blackwell, K.J. \& Gerhardt, H.C. (2001). Individual variation in advertisement calls of territorial male green frogs, Rana clamitans: Implications for individual discrimination. - Ethology 107, p. 65-84.

Campbell, N.A. \& Atchley, W.R. (1981). The geometry of canonical variate analysis. — Syst. Zool. 30, p. 268-280.

Chruszcz, B. (1995). Song variation and winter dominance in the black-capped chickadee (Parus atricapillus). - B.Sc. Hons. Thesis. Queen's University, Kingston, Ontario.

Christie, P.J., Mennill, D.J. \& Ratcliffe, L.M. (in press). Pitch shifts and song structure indicate male quality in the dawn chorus of black-capped chickadees. - Behav. Ecol. Sociobiol. 
Dabelsteen, T., Larsen, O. \& Pedersen, S.B. (1993). Habitat induced degradation of sound signals: quantifying the effects of communication sounds and bird location on blur ratio, excess attenuation, and signal-to-noise ratio in blackbird song. - J. Acoust. Soc. Am. 93, p. 2206-2220.

— — \& Pedersen, S. (1993). Song-based species discrimination and behaviour assessment by female blackbirds, Turdus merula. - Anim. Behav. 45, p. 759-771.

Desrochers, A. (1990). Sex determination of black-capped chickadees with a discriminant analysis. - J. Field Ornith. 61, p. 79-84.

Dhondt, A.A. \& Lambrechts, M.M. (1992). Individual voice recognition in birds. — Trends Ecol. Evol. 7, p. 178-179.

Endler, J.A. (2000). Evolutionary implications of the interaction between animal signals and the environment. - In: Animal signals: signalling and signal design in animal communication (Y. Espmark, T. Amundsen \& G. Rosenquist, eds). Tapir Academic Press, Norway, p. 11-46.

Evans, E. (1999). Fine structural analysis of the song of high and low ranking male blackcapped chickadees (Poecile atricapillus). - B.Sc. Hons. Thesis. Queen's University, Kingston, Ontario.

Falls, J.B. (1982). Individual recognition by sound in birds. - In: Acoustic communication in birds, Vol. 2 (D.E. Kroodsma \& E.H. Miller, eds). Academic Press, New York, p. 237278.

Ficken, M.S., Weise, C.M. \& Popp, J.W. (1990). Dominance rank and resource access in winter flocks of black-capped chickadees. - Wilson Bull. 102, p. 623-633.

Forstmeier, W., Kempenaers, B., Meyer, A. \& Leisler, B. (2002). A novel song parameter correlates with extra-pair paternity and reflects male longevity. - Proc. R. Soc. Lond. B 269, p. 1479-1485.

Fotheringham, J.R. \& Ratcliffe, L. (1995). Song degradation and estimation of acoustic distance in black-capped chickadees (Parus atricapillus). — Can. J. Zool. 73, p. 858-868.

Gentner, T.Q. \& Hulse, S.H. (1998). Perceptual mechanisms for individual vocal recognition in European starlings, Sturnus vulgaris. - Anim. Behav. 56, p. 579-594.

Godard, R. (1991). Long-term memory of individual neighbours in a migratory songbird. Nature 350, p. 228-229.

Guilford, T. \& Dawkins, M.S. (1991). Receiver psychology and the evolution of animal signals. - Anim. Behav. 42, p. 1-14.

Hailman, J.P. (1989). The organization of major vocalizations in the Paridae. — Wilson Bull. 101, p. 305-343.

Horn, A.G., Leonard, M.L., Ratcliffe, L., Shackleton, S.A. \& Weisman, R.G. (1992). Frequency variation in songs of black-capped chickadees (Parus atricapillus). - Auk 109, p. 847-852.

Kroodsma, D.E., Byers, B.E., Halkin, S.L., Hill, C., Minis, D., Bolsinger, J.R., Dawson, J., Donelan, E., Farrington, J., Gill, F.B., Houlihan, P., Innes, D., Keller, G., Macaulay, L., Marantz, C.A., Ortiz, J., Stoddard, P.K. \& Wilda, K. (1999). Geographic variation in black-capped chickadee songs and singing behavior. - Auk 116, p. 387-402.

Lambrechts, M.M. (1996). Organization of birdsong and constraints on performance. - In: Ecology and evolution of acoustic communication in birds (D.E. Kroodsma \& E.H. Miller, eds). Cornell University Press, Ithaca, p. 305-320.

— — \& Dhondt, A.A. (1988). The anti-exhaustion hypothesis: a new hypothesis to explain song performance and song switching in the great tit. - Anim. Behav. 36, p. 327-334. 
Marler, P. 1960. Bird songs and mate selection. — In: Animal sounds and communication (W.E. Lanton \& W.N. Tavolga, eds). American Institute of Biological Sciences, Washington, D.C., p. 348-367.

Mathevon, N., Aubin, T. \& Dabelsteen, T. (1996). Song degradation during propagation: Importance of song post for the wren Troglodytes troglodytes. — Ethology 102, p. 397412.

McGregor, P.K. (1991). The singer and the song: on the receiving end of bird song. — Biol. Rev. 66, p. 57-81.

— — \& Krebs, J.R. (1984). Sound degradation as a distance cue in great tit (Parus major) song. - Behav. Ecol. Sociobiol. 16, p. 49-56.

Meigs, J.B., Smith, D.C. \& Van Buskirk, J. (1983). Age determination of black-capped chickadees. - J. Field Ornithol. 54, p. 283-286.

Mennill, D.J., Ramsay, S.M., Boag, P.T. \& Ratcliffe, L.M. (in press). Patterns of extra-pair mating in relation to male dominance status and female nest placement in black-capped chickadees. - Behav. Ecol.

— —, Ratcliffe, L.M. \& Boag, P.T. (2002). Female eavesdropping on male song contests in songbirds. - Science 296, p. 873.

Morton, E.S. (1986). Predictions from the ranging hypothesis for the evolution of long distance signals in birds. - Behaviour 99, p. 65-86.

Naguib, M. (1995). Auditory distance assessment of singing conspecifics in Carolina wrens: The role of reverberation and frequency attenuation. - Anim. Behav. 50, p. 1297-1307.

- - (1996). Auditory distance estimation in song birds: Implications, methodologies and perspectives. - Behav. Proc. 38, p. 163-168.

- - (1997). Ranging of songs of Carolina wrens: effects of familiarity with the song type on use of different cues. - Behav. Ecol. Sociobiol. 40, p. 385-393.

Nelson, B.S. \& Stoddart, P.K. (1998). Accuracy of auditory distance and azimuth perception by a passerine bird in natural habitat. - Anim. Behav. 56, p. 467-477.

Nowicki, S. (1987). Vocal tract resonances in oscine bird sound production: evidence from birdsongs in a helium atmosphere. - Nature 325, p. 53-55.

- - , Hasselquist, D., Bensch, S. \& Peters, S. (2000). Nestling growth and song repertoire size in great reed warblers: evidence for song learning as an indicator mechanism in mate choice. - Proc. R. Soc. Lond. B 267, p. 2419-2424.

— —, Peters, S. \& Podos, J. (1998). Song learning, early nutrition and sexual selection in songbirds. - Am. Zool. 38, p. 179-190.

Otter, K., Chruszcz, B. \& Ratcliffe, L. (1997). Honest advertisement and song output during the dawn chorus of black-capped chickadees. - Behav. Ecol. 8, p. 167-173.

— - Ramsay, S.M. \& Ratcliffe, L. (1999). Enhanced reproductive success of female blackcapped chickadees mated to high ranking males. - Auk 116, p. 345-354.

— — \& Ratcliffe, L. (1993). Changes in singing behaviour of male black-capped chickadees (Parus atricapillus) following mate removal. - Behav. Ecol. Sociobiol.33, p. 409-414.

— — \& — (1996). Female initiated divorce in a monogamous songbird: abandoning mates for males of higher quality. - Proc. R. Soc. Lond. B 263, p. 351-354.

— — , — — Boag, P.T. (1994). Extra-pair paternity in the black-capped chickadee. — Condor 96, p. 218-222.

— —, — - Michaud, D. \& Boag, P.T. (1998). Do female black-capped chickadees prefer high-ranking males as extra-pair partners? - Behav. Ecol. Sociobiol. 43, p. 25-36. 
Phillmore, L.S., Sturdy, C.B., Ramsay, S.M. \& Weisman, R.G. (1998). Discrimination of auditory distance cues by black-capped chickadees (Poecile atricapillus) and zebra finches (Taeniopygia guttata). - J. Comp. Psych. 112, p. 282-291.

— - , — - Turyk, M.M. \& Weisman, R.G. (2002). Discrimination of individual vocalizations by black-capped chickadees (Poecile atricapillus). — Anim. Learn. Behav. 30, p. 43-52.

Podos, J. (1996). Motor constraints on vocal development in a songbird. — Anim. Behav. 51, p. 537-551.

- - (2001). Correlated evolution of morphology and vocal signal structure in Darwin's finches. - Nature 409, p. 185-188.

Ramsay, S.M., Otter, K.A., Mennill, D.J., Ratcliffe, L.M. \& Boag, P.T. (2000). Divorce and extrapair mating in female black-capped chickadees (Parus atricapillus): separate strategies with a common target. - Behav. Ecol. Sociobiol. 49, p. 18-23.

Ratcliffe, L.M. \& Otter, K. (1996). Sex differences in song recognition. — In: Ecology and evolution of acoustic communication in birds (D.E. Kroodsma \& E.H. Miller, eds). Cornell University Press, Ithaca, p. 339-355.

Rice, W.R. (1989). Analyzing tables of statistical tests. - Evolution 43, p. 223-225.

Ryan, M.J. \& Brenowitz, E.A. (1985). The role of body size, phylogeny, and ambient noise in the evolution of bird song. - Am. Nat. 126, p. 87-100.

Searcy, W.A. (1992). Measuring response of female birds to male song. — In: Playback and studies of animal communication (P.K. McGregor, ed.). Plenum Press, New York, p. $175-189$.

— — \& Yasukawa, K. (1996). Song and female choice. — In: Ecology and evolution of acoustic communication in birds (D.E. Kroodsma \& E.H. Miller, eds). Cornell University Press, Ithaca, p. 454-473.

Shackleton, S.A. (1991). The singing behaviour of the black-capped chickadee (Parus atricapillus). - M.Sc. Thesis. Queen's University, Kingston, Ontario.

— _, Ratcliffe, L. \& Weary, D.M. (1992). Relative frequency parameters and song recognition in black-capped chickadees. - Condor 94, p. 782-785.

Silva, A.P.D. \& Stam, A. (1995). Discriminant Analysis. - In: Reading and understanding multivariate statistics (L.G. Grimm \& P.R. Yarnold, eds). American Psychological Association, Washington, D.C., p. 277-318.

Smith, S.M. (1991). The black-capped chickadee: Behavioural ecology and natural history. - Cornell University Press, Ithaca, NY.

Sokal, R.R. \& Rohlf, F.J. (1995). Biometry, 3rd Ed. — Freeman, New York.

Stoddart, P.K. (1996). Vocal recognition of neighbors by territorial passerines. - In: Ecology and evolution of acoustic communication in birds (D.E. Kroodsma \& E.H. Miller, eds). Cornell University Press, Ithaca, p. 356-374.

Suthers, R.A. \& Goller, F. (1997). Motor correlates of vocal diversity in songbirds. - In: Current ornitholology. Vol. 14 (V. Nolan Jr., E.D. Ketterson \& C.F. Thompson, eds). Plenum Press, New York, p. 235-287.

— — - — — Pytte, C. (1999). The neuromuscular control of birdsong. — Philos. Trans. R. Soc. Lond. (B Biol. Sci.) 354, p. 927-939.

Vallet, E., Beme, I. \& Kreutzer, M. (1998). Two-note syllables in canary songs elicit high levels of sexual display. - Anim. Behav. 55, p. 291-297.

Weary, D.M. \& Krebs, J.R. (1992). Great tits classify song by individual voice characteristics. - Anim. Behav. 43, p. 283-287. 
Weisman, R., Ratcliffe, L., Johnsrude, I. \& Hurly, T.A. (1990). Absolute and relative pitch production in the song of the black-capped chickadee. - Condor 92, p. 118-124.

- $-\&-\ldots$ (1989). Absolute and relative pitch processing in black-capped chickadees (Parus atricapillus). - Anim. Behav. 38, p. 685-692.

Wiley, R.H. \& Richards, D.G. (1982). Adaptations for acoustic communication in birds: sound transmission and signal detection. - In: Acoustic communication in birds, Vol. 1, (D.E. Kroodsma \& E.H. Miller, eds). Academic Press, New York, p. 131-181. 